\title{
La comprensión simbólica de imágenes digitales que representan acciones dirigidas hacia un fin
}

\section{Symbolic Comprehension of Digital Images that Represent Goal Directed fictions f compreensão simbólica de imagens digitais que representam ações dirigidas a um fim}

\author{
Daniela Eva Jauck*, Olga Alicia Peralta** \\ Instituto Rosario de Investigaciones en Ciencias de la Educación (IRICE-CONICET)
}

Universidad Abierta Interamericana

Doi: http://dx.doi.org/10.12804/revistas.urosario.edu.co/apl/a.5070

\section{Resumen}

Los dispositivos digitales están cada vez más presentes en la vida cotidiana y han comenzado a utilizarse en la comunicación y en el aprendizaje a edades muy tempranas. Aunque padres y educadores suponen que los pequeños comprenden la función simbólica de sus imágenes, en tanto representaciones de la realidad, la incipiente pero creciente investigación en el área no ha arrojado resultados claros al respecto. El objetivo del presente estudio fue indagar si los niños pequeños comprenden que las imágenes provistas por una tableta representan acciones que ocurren en la realidad. Se presentó a niños de 24, 30 y 36 meses de edad secuencias de imágenes de acciones cotidianas sin mostrar el resultado de la acción. Luego de observar la secuencia, los niños debían escoger un objeto real que ostentaba el resultado de la acción. Se encontró que a los 30 y
36 meses los niños comprenden no solo la acción en sí misma, sino que las imágenes de la tableta representan una acción real, ya que eligieron el objeto que mostraba el resultado de la acción. Los resultados se discuten en torno tanto a la comprensión de acciones dirigidas hacia un fin como en cuanto a la comprensión simbólica de las imágenes que las representan.

Palabras clave: comprensión simbólica, imágenes, acciones.

\section{fibstract}

Electronic devices are increasingly present in our everyday lives. These devices are starting to be used in communication and learning at very early ages. Although parents and educators suppose that small children understand the symbolic function of their images, incipient but growing research in the area has not yet

* Becaria Doctoral del Consejo Nacional de Investigaciones Científicas y Técnicas (CONICET), Argentina. Profesora Asociada de Taller de Integración III, Universidad Abierta Interamericana

** Investigadora Principal del Consejo Nacional de Investigaciones Científicas y Técnicas (CONICET), Argentina. Profesora titular de Psicología Educacional, Universidad Abierta Interamericana. Correspondencia. Correo electrónico: peralta@irice-conicet. gov.ar

Cómo citar este artículo: Jauck, D. E., \& Peralta, O. A. (2017). La comprensión simbólica de imágenes digitales que representan acciones dirigidas hacia un fin. Avances en Psicología Latinoamericana, 35(3), 601-614. doi: http://dx.doi.org/10.12804/ revistas.urosario.edu.co/apl/a.5070 
produced clear results. The aim of this study was to investigate whether young children understand that the images provided by a tablet represent actions that can occur in reality. We presented to 24-, 30- and 36-month-old children sequences of images of everyday actions without showing the results of those actions. Then the children had to choose real objects that exhibit the result of the action that had been presented. We found that 30-month and 36-month-old, but not 24-month-old children, understood not only the actions themselves but that the images they saw represented real actions, correctly choosing the objects that showed the results of the actions presented. The results of the study are discussed with respect to the comprehension of goal-directed actions and regarding the symbolic comprehension of the images representing such actions.

Keywords: Symbolic comprehension, images, actions.

\section{Resumo}

Os dispositivos digitais estão cada vez mais presentes na vida cotidiana e têm começado a se utilizar na comunicação e na aprendizagem a idades muito prematura. Ainda que pais e educadores supõem que os pequenos compreendem a função simbólica das suas imagens enquanto representações da realidade, a incipiente, mas crescente pesquisa na área não tem mostrado resultados claros ao respeito. O objetivo do presente estudo foi indagar se as crianças pequenas compreendem que as imagens providas por uma tablet representam ações que ocorrem na realidade. Apresentamos a crianças de 24, 30 e 36 meses de idade sequencias de imagens de ações cotidianas sem mostrar o resultado da ação. Após observar a sequência as crianças deviam escolher um objeto real que ostentava o resultado da ação. Encontramos que aos 30 e 36 meses as crianças compreendem não só a ação em si mesma, senão que as imagens da tablet representam a uma ação real, devido a que escolheram o objeto que mostrava o resultado da ação. Os resultados discutem-se em torno tanto à compreensão de ações dirigidas a um fim, quanto à compreensão simbólica das imagens que as representam.
Palavras-chave: compreensão simbólica, imagens, ações.

Los teléfonos inteligentes, las tabletas y las cámaras digitales están siendo cada vez más utilizadas en distintos ámbitos por adultos y niños, inclusive a edades muy tempranas. El empleo de estos dispositivos electrónicos por parte de niños pequeños ha despertado fuertes controversias (Christakis \& Zimmerman, 2009; American Academy of Pediatrics, 2011). Algunos autores, incluso, han sugerido que la televisión y los dispositivos electrónicos están desplazando la interacción social, como jugar o conversar (Walsh, 2005). Sin embargo, otros autores sostienen que estos efectos negativos solo se han observado en niños muy pequeños y en aquellos que los emplean por espacios de tiempo prolongados (Rodríguez, 2012).

Más allá de las discusiones relacionadas con sus posibles ventajas o desventajas, estos dispositivos han comenzado a funcionar como un nuevo soporte en la enseñanza y la comunicación desde los primeros años de vida (Barr, 2013; Kirkorian \& Pempek, 2013; Richet, Robb \& Smith, 2011; Zack, Barr, Gerhardstein, Dickerson \& Meltzoff, 2009). Sin embargo, si se pretende enseñar y comunicar a través de estos medios resulta importante, en primer lugar, estudiar si los niños comprenden la función simbólica de sus imágenes, es decir, si comprenden que las imágenes dicen algo acerca de la realidad.

El objetivo del presente estudio fue indagar si los niños de 24, 30 y 36 meses de edad comprenden que las imágenes provistas por una tableta representan acciones dirigidas hacia un fin que ocurren en la realidad. De esta manera, el trabajo se nutre de dos vertientes: la comprensión simbólica de imágenes y la comprensión de acciones dirigidas hacia un fin. 


\section{Las imágenes como símbolos}

Cuando se habla de símbolo en el campo de la filosofía y la psicología, no todos los pensadores concuerdan con esto. Los teóricos han considerado en formas muy diferentes e incluso inconsistentes a términos tales como símbolo, signo, señal, índice, ícono. Algunos, como el filósofo Pierce y los psicólogos Bruner, Olver y Greenfield reservan el 'símbolo' para entidades que tienen relaciones puramente arbitrarias, formales, convencionales con lo que representan, por ejemplo, una palabra. Para otros, el término 'símbolo' es usado de una manera amplia, adoptando la postura de Goodman, quien plantea que "cualquier cosa puede representar a casi cualquier cosa" (1976, p. 5). Para este autor, ni la similitud entre símbolo y referente, ni la arbitrariedad son condiciones sine qua non para que una entidad sea considerada un símbolo. En este sentido, compartimos la definición propuesta por DeLoache (2004), quien considera a los símbolos como "aquellas entidades que alguien propone para representar algo diferente" (p. 66). Lo que hace que algo sea simbólico, entonces, es la intención humana; una entidad se convierte en un símbolo solamente como resultado de que una persona lo use para denotar o referir a algo. Por lo tanto, el corazón de un símbolo es su dimensión intencional, dimensión que debe ser percibida para su uso convencional (Bloom \& Markson, 1998; Callaghan, 2008; Gelman \& Ebeling, 1998; Tomasello, 1999; Salsa \& Peralta, 2007).

En cada cultura existen diferentes clases de símbolos. Algunos, como ciertas figuras religiosas, son comprendidos principalmente por poseer una evocación emocional sin tener un contenido específico. Otros, como la escritura o los sistemas numéricos, son conjuntos de símbolos carentes en sí mismos de significado intrínseco pero que proveen información cuando son combinados de modo sistemático.

Los artefactos u objetos simbólicos, por su parte, son entidades reales que contienen y transmiten información específica. Los objetos simbólicos son objetos concretos y, a la vez, son entidades que representan otra cosa, es por ello que tiene una realidad doble (DeLoache, 1987, 2004). Los objetos simbólicos pueden ser tridimensionales, como las réplicas, o bidimensionales, como los gráficos. A su vez, algunos de estos símbolos, como los modelos a escala y fotografías, guardan una alta similitud con sus referentes mientras que otros, como por ejemplo los mapas o expresiones artísticas modernas, son representaciones más abstractas de sus referentes.

\section{La comprensión simbólica de imágenes}

Dentro de la gran variedad de objetos simbólicos se encuentran las imágenes. Las imágenes inundan nuestro entorno y tienen diversos formatos, pudiendo ser encontradas en medios impresos como libros, fotos, etiquetas, revistas o en formatos análogos o digitales como las que observamos en las computadoras, carteles publicitarios, teléfonos celulares, entre otros.

Como desde muy pequeños los niños reconocen e incluso nombran los objetos representados en imágenes y los diferencian de sus contrapartidas reales, discriminando entre las imágenes y sus referentes, frecuentemente se supone que comprenden la relación simbólica que las une con lo que representan. Estos supuestos han contribuido a una interpretación errónea al considerar que los bebés comprenden la relación simbólica que une a las imágenes con lo que representan de forma casi automática. Sin embargo, como ya lo señalara Sigel (1978), este error interpretativo surge de no distinguir reconocimiento y percepción de comprensión simbólica. Mientras que el reconocimiento solo requiere habilidades perceptuales, la comprensión requiere de un entramado de habilidades cognitivas, sociales y perceptuales. Comprender el rol representacional de imágenes implica la decodificación de la información presente en ellas y su vinculación con lo que representan (Ittelson, 1996). 
La comprensión simbólica de imágenes implica un largo camino. Una explicación sobre el origen de las dificultades en la comprensión de imágenes, como de todo objeto simbólico en general, se ha centrado en su naturaleza doble, ya que se trata de objetos en sí mismos y a la vez de representaciones de otra entidad (DeLoache, 1987, 2004). Para entender y utilizar las imágenes como objetos simbólicos, se necesita la representación mental simultánea de ambas facetas de su realidad dual: sus características concretas y su relación abstracta con lo que representan. Los niños pequeños no muestran esta flexibilidad cognitiva, ven al objeto simbólico como un objeto en sí mismo, lo que les impide ver por medio de este a su referente (Ittelson, 1996). Investigaciones que han tratado de acentuar las características físicas de una imagen, incrementando sus propiedades en tanto objetos, por ejemplo, presentando un libro con ilustraciones desplegables y manipulables, han mostrado que los niños tienen mayores dificultades para establecer la relación simbólica entre las imágenes y la realidad (Tare, Chiong, Ganea \& DeLoache, 2010).

El impacto de la representación dual en la comprensión simbólica de imágenes también fue testeado en numerosas investigaciones que han utilizado una tarea de búsqueda (DeLoache, 1987). En esta tarea, la ubicación de un juguete escondido en un espacio (una habitación) es proporcionada señalando en una imagen la localización del juguete. Para poder resolver la tarea los niños deben tomar a la imagen como un objeto simbólico comprendiendo que la imagen representa al espacio de búsqueda. Estas investigaciones claramente establecieron que si a los niños se les provee instrucciones acerca de la función simbólica de una imagen (fotografías o dibujos), a los dos años y medio de edad, pero no a los dos, utilizan la imagen como fuente de información para resolver la tarea (DeLoache \& Burns, 1994; Peralta \& Salsa, 2011; Salsa \& Peralta, 2007; Schmitt \& Anderson, 2002). Los resultados encontrados con imágenes impresas fueron replicados utilizando imágenes en video
(Troseth, 2003; Troseth \& DeLoache, 1998). Estas investigaciones apoyan la hipótesis de que una fuente de dificultad que tienen los niños se debe a la necesidad de mantener una orientación doble hacia el símbolo.

Por otra parte, Anderson y Pempek (2005) mostraron que los niños pequeños aprenden menos de la televisión y de los videos que de las experiencias provenientes de la vida real. Este último fenómeno denominado "el efecto del déficit del video" se ha explicado de varias maneras. Por ejemplo, una de las explicaciones ha propuesto que las imágenes no ofrecen a los niños pequeños la misma cantidad y calidad de detalles que se obtienen de la vida real, lo cual limita la transferencia de la información a la realidad (Barr, 2008; Krcmar, 2010; Richert, Robb \& Schmitt, 2011; Schmitt \& Anderson, 2002; Zack et al., 2009). Sin embargo, otros estudios han encontrado que cuando la información presentada es relevante y se acompaña de interacción puede promover procesos de transferencia de información de la pantalla a la cotidianeidad (Nielsen, Simcock, Jenkins, 2008; Rosberry, Hirsh-Pasek, \& Golinkoff, 2014; Troseth, Saylor, \& Archer, 2006).

\section{La comprensión de acciones dirigidas hacia un fin}

Está ampliamente demostrado que los niños desde los primeros meses de vida comprenden las acciones realizadas por otros en el mundo y las interpretan en función de "relaciones dirigidas hacia un fin" (Baird, Saylor \& Clark, 2001; Barresi \& Moore, 1996; Woodward, 1998; Woodward et al., 2009). Cuando los niños observan acciones, no ven simples movimientos en el espacio, sino movimientos organizados entre agentes y sus objetivos en contextos específicos (Woodward \& Gerson, 2015).

A lo largo de los primeros años de vida, la capacidad de leer significados en señales sociales se vuelve cada vez más sofisticada. Por ejemplo, a los doce meses los bebés utilizan señales tales 
como la mirada para sacar conclusiones acerca de las metas de un actor y usan esta información para interpretar su mundo (Baldwin \& Moses, 2001; Woodward, 2003, 2009). A los quince meses, los bebés deducen las intenciones subyacentes en secuencias continuas de acciones novedosas (Meltzoff, 1995, 1999) y hacen uso flexible de los indicios que otros proporcionan para guiar tales inferencias (Baldwin, 2000; Tomasello, 1999). La mayoría de las acciones humanas, a diferencia de los eventos físicos, se caracterizan porque están dirigidas a una meta u objetivo determinado, lo que ha llevado a algunos teóricos a proponer que la comprensión de eventos físicos y acciones humanas se constituyen en dominios bien diferenciados (Dennett, 1987; Kellman \& Spelke, 1983; Spelke et al., 1995).

Cabe aclarar que el concepto meta u objetivo ha resultado problemático, ya que este término ha sido intercambiable con el término "intención"; de esta forma, las acciones son procedentes de los estados mentales. Sin embargo, los términos objetivo o meta pueden ser conceptualizados a un nivel conductual, en el sentido de aquello que es perceptible en la conducta (Jovanic, et al., 2007).

Los niños pueden interpretar los objetivos de las acciones de los demás en términos psicológicos (Gergely \& Csibra, 2003; Leslie, 1995; Onishi \& Baillargeon, 2005; Premack \& Premack, 1995) o en términos puramente conductuales (Jovanic, et al., 2007). En este sentido, el análisis de la conducta observable puede ser suficiente para que los niños pequeños logren comprender acciones sin necesidad de referir al estado mental, a intenciones o deseos, al menos en sus inicios.

Un estudio documentó que niños de once meses comprenden acciones cotidianas y extraen información presentada mediante imágenes de video, cuando estas acciones son desarrolladas de manera continua y en secuencias coincidentes con los límites de los objetivos de un actor (Saylor, Baldwin, Baird \& LaBounty, 2007). La interpretación del comportamiento de los demás dirigido hacia un fin parecería depender crucialmente de la capacidad de segmentar la acción continua en unidades relevantes.

Algunos autores (Brune \& Woodward, 2007; Meltzoff \& Moore, 1997; Gerson \& Woodward, 2013; Somerville, Woodward \& Needham, 2005) han propuesto que en realidad es la experiencia que los niños tienen sobre sus propias acciones lo que les permite reconocer y comprender las acciones que otros desempeñan. Es por ello que las acciones pueden ofrecer un marco seductor para investigar si la información provista por imágenes provee a los niños de información útil acerca de lo que ocurre en su mundo real.

\section{La comprensión de imágenes como representaciones de acciones reales}

Los estudios sobre comprensión de acciones por parte de bebés y niños pequeños en su gran mayoría se realizaron con secuencias presentadas en imágenes de video. El niño observaba un fragmento del video y luego debía anticipar el resultado de la acción. Se utilizaron técnicas tales como la mirada preferencial (Saylor, Baldwin, Baird \& LaBounty, 2007; Woodward, 1998) o el uso de eye trackers (Falck-Ytter, Gredebäck \& von Hofsten, 2006; Flanagan \& Johansson, 2003). La finalidad de esos estudios era la comprensión de la acción en sí misma, y no si el video representaba, simbolizaba o refería una acción que podía tener lugar en la realidad.

Un estudio que en alguna medida unió ambas vertientes - comprensión de acciones y comprensión simbólica de imágenes que representan acciones - fue el realizado por Harris, Kavanaugh y Dowson (1997). Estos autores investigaron la utilización de imágenes impresas para comunicar información acerca de acciones reales o imaginarias efectuadas sobre un objeto real. En la tarea, los niños debían seleccionar una fotografía (entre tres) que mostrara el resultado de una acción en la que el experimentador volcaba o "hacía como si" 
volcara salsa sobre un juguete. Los niños menores a 28 meses seleccionaron las imágenes al azar, pero los mayores fueron muy exitosos al seleccionar la que mostraba el resultado de la acción. Este estudio mostró que los niños no solo comprendían la acción en sí misma, o que solo realizaban una correspondencia perceptual imagen-objeto, sino que tomaban a las imágenes en forma simbólica, como una representación de una acción que tiene lugar en la realidad.

La investigación que aquí se presenta une ambas vertientes: comprensión de acciones y comprensión simbólica de imágenes. Su objetivo consiste en indagar si los niños de 24, 30 y 36 meses de edad comprenden que las secuencias de imágenes digitales provistas por una tableta representan acciones dirigidas hacia un fin que ocurren en la realidad.

\section{Metodología}

Participantes. Participaron 45 niños, 15 de 24 meses $(\mathrm{R}=24-27 ; M=25,67 ; S T=1,49 ; 9$ niños y 6 niñas), 15 de 30 meses ( $\mathrm{R}=28-31 ; M=29,40$; $S T=0,73 ; 7$ niños y 8 niñas) y 15 de 36 meses de edad $(\mathrm{R}=33-38 ; M=36,20 ; S T=1,20 ; 6$ niños y 9 niñas). Los niños asistían a jardines maternales y escuelas de gestión pública y privada localizadas en una ciudad de tamaño mediano del centro de la República Argentina (Santa Elena, provincia de Entre Ríos). A estas instituciones acude mayoritariamente una población de nivel socioeconómico medio. El nivel sociocultural de todos los participantes fue corroborado con datos sobre escolaridad y ocupación. Los padres y madres contaban con escolaridad secundaria completa, o terciaria o universitaria, completa o incompleta. Al menos uno de los padres trabajaba en su respectivo oficio, comercio o profesión. Según los datos proporcionados por los padres, la institución y el personal a cargo, todos los niños tenían un desarrollo (motriz, cognitivo, lingüístico) esperado para su edad y no contaban con antecedentes patológicos. La mayoría de los niños había tenido algún tipo de experiencia con medios digitales con pantallas táctiles, tales como teléfonos inteligentes, computadoras portátiles y tabletas, fundamentalmente con fines lúdicos. En todos los casos se contó con el consentimiento informado de los padres y de la institución.

Materiales. Se utilizó una tableta de 10,1", en la que se presentaron secuencias de imágenes que representaban acciones dirigidas hacia un fin, simples y cotidianas, realizadas por una figura humana. También se utilizaron nueve objetos reales que aparecían en las imágenes: papeles, manzanas de juguete y ositos de peluche. Las imágenes se seleccionaron con base en un estudio piloto donde se exploró la comprensión de acciones representadas por animales de juguete y figuras humanas. Debido a que las acciones ejecutadas por animales hacían dificultoso el procedimiento experimental, ya que los niños centraban su atención en los animales en sí mismos al resultarles muy atractivos, se optó por acciones realizadas por una figura humana. Esta figura no mostraba el rostro para neutralizar pistas ostensivas, solo el torso y/o los brazos y las manos con el objetivo de que la atención se focalizase en la acción ejecutada sobre los objetos (figura 1).

Procedimiento. Se diseñó una tarea en la cual el niño observaba las diferentes acciones en una secuencia de imágenes presentadas en la tableta. Estas imágenes mostraban la secuencia, pero no el resultado final. Luego de observar cada secuencia, el niño debía elegir un objeto que ostentara el resultado de la acción escogiendo una de tres opciones posibles: (i) objeto con la modificación correcta, (ii) objeto sin modificación alguna, (iii) objeto con otra modificación.

Para comenzar, la experimentadora invitaba a los niños a sentarse en una mesa donde estuvieran cómodos y pudieran observar las imágenes proyectadas en la tableta. Sobre la mesa se encontraban las elecciones ocultas por unas telas opacas. El procedimiento constaba de dos fases:

Orientación: En esta fase se presentaba a los niños tres secuencias de acciones en imágenes y 
mientras se mostraban las imágenes se les preguntaba “¿Qué está haciendo?”. Al finalizar la presentación se decía el resultado la acción (e. g. Secuencia 1: ¿Qué está haciendo?... viste como abrió). El propósito de esta fase era asegurarse de que los niños prestasen atención a la acción representada.

Prueba: Esta fase constaba de tres subpruebas (tres secuencias). Se mostraban las secuencias en forma sucesiva, en cada una de ellas se preguntaba a los niños nuevamente: “¿Qué está haciendo?”, sin relatarles verbalmente la acción. Inmediatamente después de mostrar cada secuencia, se invitaba a los niños elegir el objeto con el resultado de la acción diciendo: “¿Me muestras cómo quedó?”.

El orden de presentación de las secuencias y elecciones fue contrabalanceado.

La figura 1 muestra las secuencias de acciones en imágenes (fases de orientación y prueba). También presenta las opciones de elección de objetos de la fase de prueba con el resultado de la acción.

\section{Resultados}

La variable dependiente fue el número de subpruebas correctas. Una respuesta se consideró correcta si el niño escogía el objeto con la modificación que mostraba el resultado de la acción. Se tuvo en cuenta solo la primera elección. Cada niño podía tener un mínimo de cero y un máximo de tres respuestas correctas en la prueba. Como cada grupo de edad estaba conformado por 15 participantes, el máximo puntaje posible por grupo era 45. El grupo de 24 meses exhibió 17 respuestas correctas, el de 30 meses, 32 y el de 36 meses, 39 (figura 2). Diferencias significativas fueron encontradas entre los grupos $\left(X^{2}=17,55, p<0001\right)$.

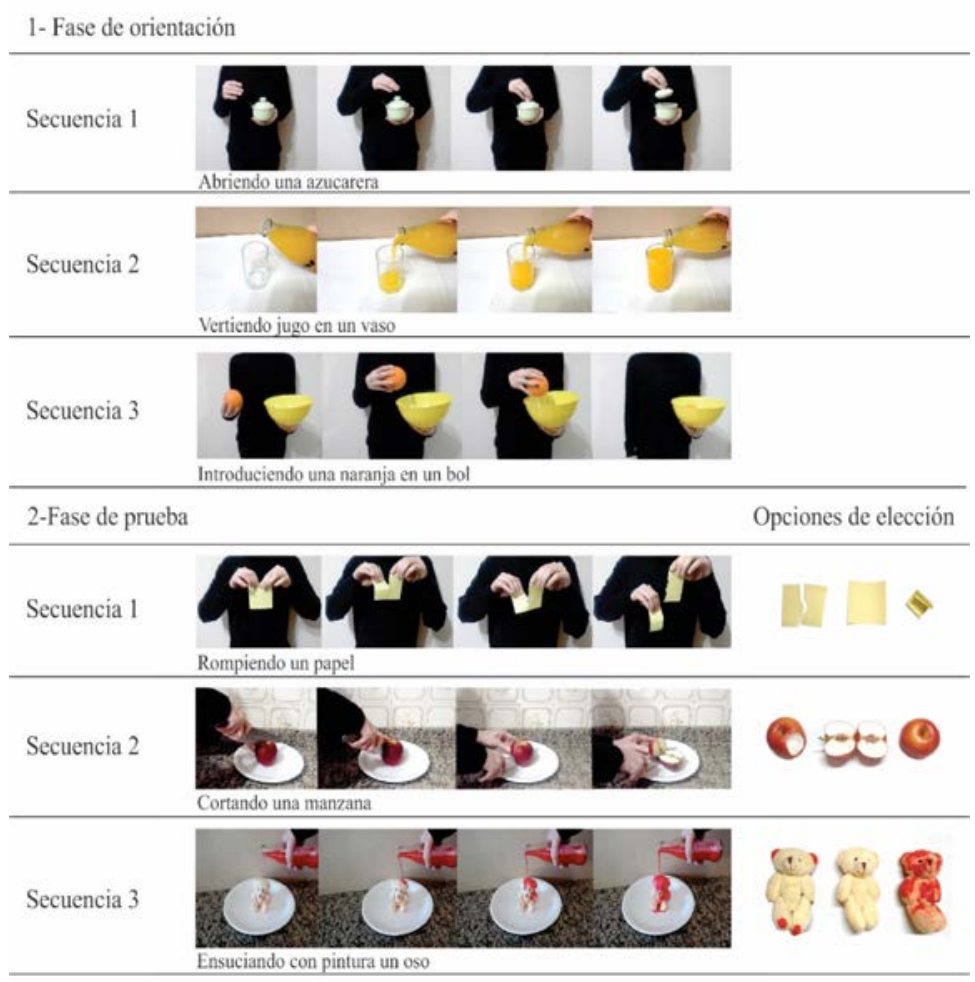

Figura 1. Secuencias de imágenes de la orientación y secuencias de imágenes de la prueba con sus respectivas Fuente: elaboración propia. 


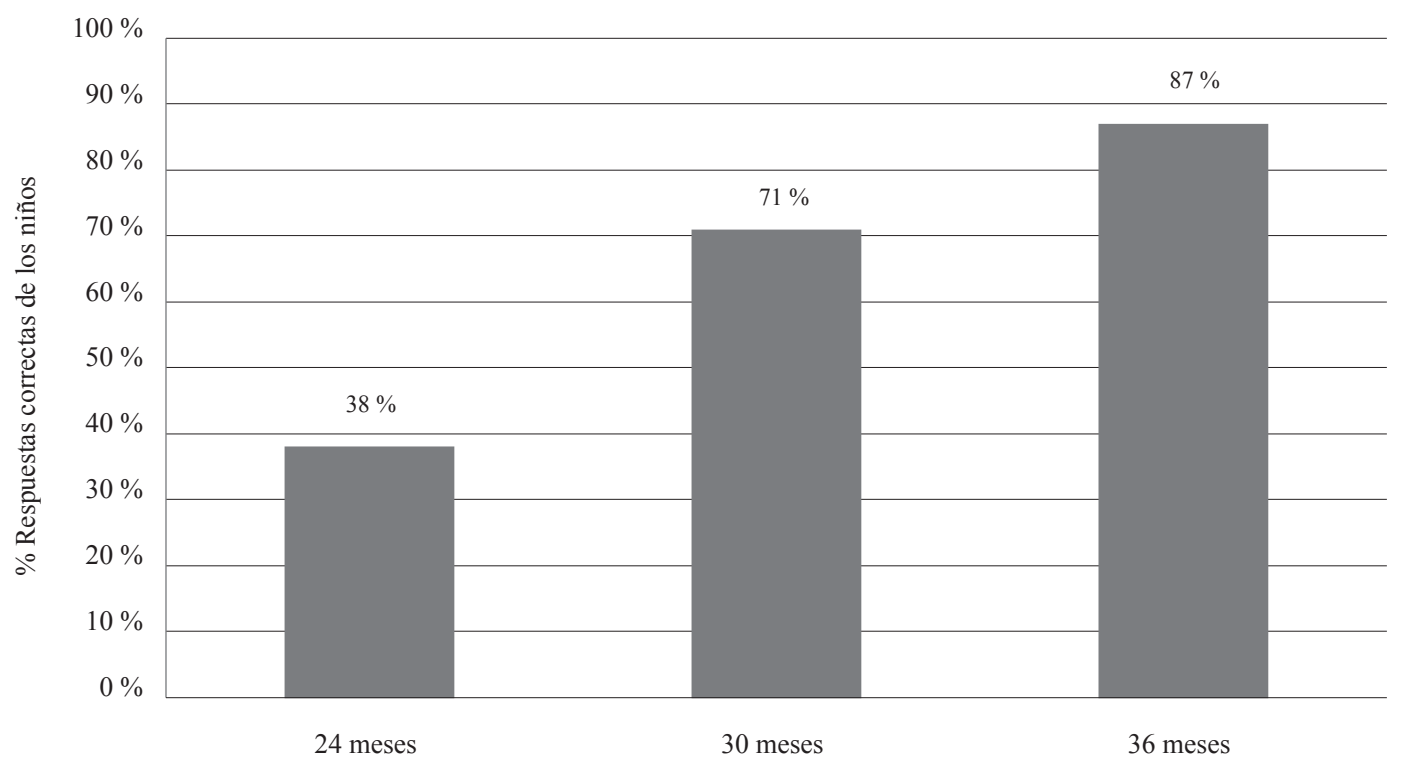

Figura 2. Porcentaje de respuestas correctas por edad Fuente: elaboración propia.

Las comparaciones por pares arrojaron diferencias significativas entre los niños de 24 y 36 meses $(U=21,00, Z=-3,80, p<0,000)$, entre los de 24 y 30 meses $(U=38,50, p<0,001)$, pero no entre los niños de 30 y 36 meses de edad (ns).

En cuanto a las respuestas correctas (RC) e incorrectas (RI) al interior de cada grupo, se encontraron diferencias significativas en el grupo de 30 meses $(\mathrm{RC}=32, \mathrm{RI}=13)\left(X^{2}=9,26 ; p<0,02\right) \mathrm{y}$ en el de 36 meses de edad $(\mathrm{RC}=39$, $\mathrm{RI}=6)\left(X^{2}=\right.$ 10,80; $p<0,005)$, con más respuestas correctas que incorrectas en ambos. En cuanto a los niños de 24 meses, si bien mostraron más respuestas incorrectas que correctas, la diferencia no alcanzó significación $(\mathrm{RC}=17$; $\mathrm{RI}=28, n s)$.

Debido a que a los niños se les presentaron acciones de diferente naturaleza (romper, cortar y ensuciar), se analizó si alguna de estas acciones era más fácil de comprender según la edad de los niños. Los niños fueron mejores en la acción de ensuciar en todas las edades; sin embargo, los resultados estadísticos no arrojaron diferencias significativas. Por otro lado, debido a que a los niños se les presentaba una opción correcta y dos incorrectas (objeto sin modificación, objeto con otra modificación), se analizó si había alguna tendencia de los niños a seleccionar una opción incorrecta por sobre otra. No se encontraron diferencias significativas entre el tipo de elección errónea que realizaron los niños en los tres grupos de edad.

También se analizó el desempeño individual. A los 24 meses, cuatro niños respondieron correctamente dos subpruebas, nueve niños una y dos niños ninguna. A los 30 meses, cinco niños respondieron correctamente todas las subpruebas; ocho niños, dos; un niño, una y un solo niño, ninguna. A los 36 meses, once niños obtuvieron la puntuación máxima, dos niños resolvieron dos y un niño una (tabla 1).

\section{Discusión}

El objetivo del presente estudio fue explorar si los niños de 24, 30 y 36 meses de edad comprenden que las imágenes provistas por una tableta representan acciones dirigidas hacia un fin que pueden ocurrir en la realidad. 
Tabla 1

Desempeño correcto individual de los niños por edad

\begin{tabular}{ccccccc}
\hline & \multicolumn{6}{c}{ Número de subpruebas correctas } \\
\cline { 2 - 7 } Edades & 0 & 1 & 2 & 3 & $\mathrm{n}$ \\
\cline { 2 - 7 } & 24 meses & 2 & 9 & 4 & - & 15 \\
& 30 meses & 1 & 1 & 8 & 5 & 15 \\
& 36 meses & - & 1 & 1 & 12 & 15 \\
\hline
\end{tabular}

Fuente: elaboración propia.

Los resultados mostraron que los niños de $30 \mathrm{y}$ 36 meses, a diferencia de los de 24, comprendieron que las secuencias de imágenes se referían a una acción real, ya que escogieron el objeto real que mostraba el resultado de la acción. Cabe destacar que las imágenes no presentaban el resultado de la acción, o sea que no se trataba de una tarea de correspondencia perceptual imagen-objeto. Para escoger el objeto con la modificación que resultaba de la acción, el niño debía interpretar la secuencia de imágenes no solo como una acción dirigida hacia un fin sino también en forma simbólica, como una representación de lo ocurre en la realidad.

Si bien se ha sugerido que las acciones poseen múltiples niveles de abstracción, lo que hace que algunas sean más sencillas que otras (Hamlin, Hallinan \& Woodward, 2008), este no pareció ser el caso de las acciones en este estudio presentadas, ya que ninguna fue más sencilla o complicada de comprender que la otra. Si bien los resultados no son directamente comparables, resulta interesante destacar que en el estudio de Harris, Kavanaugh y Dowson (1997) la acción siempre fue la misma: "ensuciar"; en ese caso el experimentador hacía como si realizaba la acción o realizaba acciones de verter algo sobre un juguete. En la presente investigación se representaron acciones de diferente naturaleza (romper, cortar y ensuciar), lo que quizás llevó a que la tarea propuesta tuviera una mayor demanda cognitiva para los niños más pequeños.

Los niños desde muy temprano tienen una amplia experiencia con acciones como las que presentamos. Ellos observan y experimentan que los objetos se rompen, mojan o ensucian cuando son manipulados por otros o por ellos mismos. Como se ha demostrado, los niños pequeños logran comprender acciones, incluso acciones incompletas (Hamlin, Hallinan \& Woodward, 2008; Carpenter, Akhtar \& Tomasello, 1998; Csibra \& Gergely, 2009). Más aun, diferencian acciones dirigidas hacia un fin de accidentes y desarrollan una cierta comprensión de la intención en la acción (Behne, Carpenter, Call \& Tomasello, 2005; Moore, Liebal \& Tomasello, 2013).

Los niños de 24 meses del presente estudio probablemente comprendieron las acciones en sí mismas en la secuencia de imágenes presentadas, pero no relacionaron simbólicamente dichas imágenes con la realidad, por lo que no pudieron escoger el objeto que mostraba el resultado de la acción. De hecho, varios de estos niños verbalizaron mientras observaban las secuencias, por ejemplo "está cortando" (manzana), "está abriendo una carta" (papel); sin embrago, fallaban a la hora de elegir el objeto.

Un resultado llamativo de este estudio fue que los niños de 30 meses fueron muy exitosos en la tarea. Investigaciones previas que han estudiado la comprensión de imágenes a esta edad han establecido que los niños necesitan de ayudas e instrucciones explícitas para utilizar las imágenes como representaciones de la realidad (DeLoache \& Burns, 1994; Peralta \& Salsa, 2011; Salsa \& Peralta, 2007).

Si bien los niños de la presente investigación no recibieron instrucciones explícitas en cuanto a la función de referencia de las imágenes, cuando se presentaban las secuencias el experimentador preguntaba “¿qué está haciendo?”. Probablemente, el uso del verbo ayudó a los niños en la tarea, ya que un verbo marca una acción. En este sentido investigaciones han mostrado que las etiquetas ayudan a la detección de similitudes y relaciones entre acciones familiares y novedosas (Gerson \& Woodward, 2013). 
Por otra parte, los niños observaban la secuencia de la acción en cuatro imágenes y tenían que indicar el resultado en un objeto real. Está ampliamente demostrado que tanto niños como adultos comprenden una acción con más rapidez si esta se presenta en una secuencia completa (Baldwin, Anderson, Saffran \& Meyer, 2008). En el presente estudio no se consideró separadamente la medida en la que podrían jugar las variables información verbal e información perceptual en la comprensión simbólica de acciones representadas en imágenes. En este sentido, se está diseñando un estudio con el propósito de desentrañar el impacto de (i) la presencia o ausencia del verbo en la consigna y (ii) la magnitud de información perceptual presentada, al variar la cantidad de imágenes de las secuencias o al mostrar la acción en forma continua (video), tal como ocurre en la realidad.

Por otra parte, otra variable que ha demostrado tener un peso importante en la comprensión simbólica es la experiencia previa (Jauck \& Peralta, 2016; Marzolf \& DeLoache, 1994; Peralta \& Salsa, 2009; Troseth, 2003). Si bien en esa investigación se indagó acerca de experiencia previa de los niños con este tipo de dispositivos, esto se realizó informalmente. En futuros estudios resultaría de interés indagar sistemáticamente este aspecto, por ejemplo, administrando un cuestionario a padres y docentes sobre la presencia y el uso de tecnología o realizando observaciones, tanto en el hogar como en ámbitos educativos.

\section{Conclusiones y perspectivas}

En esta investigación se conjugan dos líneas hasta ahora exploradas en forma separada: la comprensión de acciones y la comprensión simbólica de las imágenes que las representan. Este tipo de estudios puede tener implicancias a nivel educativo, ya que para aprender por medio de imágenes es crucial, primero y principal, comprender su rol referencial. Esto implica entender que las imágenes vienen a mostrar algo acerca del mundo.
Futuros estudios podrían indagar el uso de una tableta en contextos de aprendizaje e investigar si los niños aprenden contenidos específicos por medio de sus imágenes, no cuando el adulto manipula este dispositivo, sino permitiendo que sea el niño quien lo haga con el fin de "descubrir" y sacar provecho de sus propiedades y su pantalla táctil. En este sentido, se ha señalado que las experiencias interactivas o no interactivas utilizando pantallas táctiles tienen efectos diferenciales en la comprensión simbólica y el aprendizaje infantil (Kirkorian, Choi \& Pempek, 2016; Strouse \& Ganea, 2016; Troseth, Russo \& Strousse, 2016). Por otra parte, como Sheehan y Uttal (2016) señalaron, mientras que las investigaciones en representación dual sugieren que las propiedades manipulativas de las pantallas táctiles pueden dificultar su uso como medios simbólicos, sus propiedades interactivas pueden ayudar a superar esta dificultad.

Como ya se ha señalado, las imágenes proporcionadas por una tableta solo han comenzado a ser parte de la vida de los niños pequeños recientemente y aún no se utilizan frecuentemente para fines educativos, lo que quizá constituya una ventaja para el aprendizaje. En este sentido, se ha sugerido que la experiencia con dispositivos tan comunes como el televisor o videos puede llevar a que los niños tomen a sus imágenes como fuente de información irrelevante sobre la realidad, ya que consideran que lo que allí se observa es pura fantasía (Anderson \& Pempek, 2005; Kirkorian, Wartella \& Anderson, 2008; Schmitt \& Anderson, 2002; Strousse \& Troseth, 2008).

En síntesis, la presente investigación aporta información básica y única sobre los primeros pasos en la comprensión simbólica de imágenes que representan acciones provistas por dispositivos digitales como las tabletas y abre nuevos interrogantes. Por ejemplo, algunas preguntas pueden poner el acento en lo evolutivo, en lo educativo, en los diferentes niveles de experiencia previa y en el tipo de interacción con pantallas táctiles, así 
como en cuanto a los efectos de su exposición a largo plazo.

\section{Referencias}

Anderson, D. R., \& Pempek, T. A. (2005). Television and very young children. The American Behavioral Scientist, 48(5), 505-522. doi: 10.1177/0002764204271506

Baldwin, D. A. (2000). Interpersonal understanding fuels knowledge acquisition. Current Directions in Psychological Science, 9, 40-45. doi: 10.1111/1467-8721.00057

Baldwin, D. A., Andersson, A., Saffran, J., \& Meyer, M. (2008). Segmenting dynamic human action via statistical structure. Cognition, 106(3), 13821407. doi:10.1016/j.cognition.2007.07.005

Baldwin, D. A., Baird, J., Saylor, M., \& Clark, A. (2001). Infants parse dynamic human action. Child Development, 72, 708-717. doi: 10.1111/1467-8624.00310

Baldwin, D. A., \& Mose, J. A. (2001). Links between Social understanding and early Word learning: Challenges to current accounts. Social Development, 10, 311-329. doi: 10.1111/14679507.00168

Barr, R. (2008). Attention and learning from media during infancy and early childhood. In S. L. Calvert \& B. Wilson, The Handbook of Children, Media and Development (pp. 144-165). Malden, MA: Blackwell Publishing.

Barr, R. (2013). Memory constraints on infant learning from picture books, television, and touchscreens. Child Development Perspectives, 7(4), 205-210. doi: 10.1111/cdep.12041

Barresi, J., \& Moore, C. (1996). Intentional relations and social understanding. Behavioral and Brain Sciences, 19(1), 107-121 doi: http://dx.doi. org/10.1017/S0140525X00041881

Behne, T., Carpenter, M., \& Tomasello, M. (2005). One-year-olds comprehend the communicative intentions behind gestures in a hiding game.
Developmental Science, 8, 492-499. doi: 10.1111/j.1467-7687.2005.00440.x

Bloom, P., \& Markson, L. (1998). Intention and analogy in children's naming of pictorial representations. Psychological Science, 9, 200-204. doi: 10.1111/1467-9280.00038

Brune, C. W., \& Woodward, A. L. (2007). Social cognition and social responsiveness in 10-month-old infants. Journal of Cognition and Development, 8(2), 138-158. doi: $10.1080 / 15248370701202331$

Callaghan, T. (2008). The origins and development of pictorial symbol functioning. En C. Milbrath \& H. Trautner (Eds.), Children's Understanding and Production of Pictures, Drawing, and Art (pp. 21-32). Cambridge, MA: Hogrefe \& Huber. doi: 10.1111/j.1540-5834. 2011.00603.x

Carpenter, M., Akhtar, N., \& Tomasello, M. (1998). Fourteen through 18-month-old infants differentially imitate intentional and accidental actions. Infant Behavior and Development, 21, 315-330. doi: 10.1016/S0163 6383(98)900091

Christakis, D. A., \& Zimmerman, F. (2009). Young children and media. Limitations of current knowledge and future directions for research. American Behavioral Scientist 52(8), 11771185. doi: $10.1177 / 0002764209331540$

Csibra, G., \& Gergely, G. (2009). Natural pedagogy. Trends in Cognitive Sciences, 13, 148-153. doi:10.1016/j.tics.2009.01.005

DeLoache, J. S. (1987). Rapid change in the symbolic functioning of very young children. Science, 238(4833), 1556-1557. doi: 10.1126/ science. 2446392

DeLoache, J. S. (2004). Becoming symbol-minded. Trends in Cognitive Sciences, 8, 66-70. doi:10.1016/j.tics.2003.12.004

DeLoache, J. S., \& Burns, N. (1994). Early understanding of the representational function of pictures. Cognition, 52, 83-110. doi: 10.1016/00100277(94)90063-9

Dennett, D. (1987). The Intentional Stance. Cambridge, MA: MIT Press. 
Dirks, J., \& Gibson, E. (1977). Infants' perception of similarity between live people and their photographs. Child Development, 124-130. doi: $10.2307 / 1128890$

Falck-Ytter, T., Gredebäck, G., \& Von Hofsten, C. (2006). Infants predict other people's action goals. Nature Neuroscience, 9, 878-879. doi: 10.1038/nn1729

Flanagan J. R., \& Johansson, R. S. (2003) Action plans used in action observation. Nature, 424, 769-77. doi: 10.1038/nature01861

Gelman, S., \& Ebeling, K. (1998). Shape and representational status in children's early naming. Cognition, 66(2), 35-47. doi: 10.1016/S00100277(98)00022-5

Gergely, G., \& Csibra, G. (2003). Teleological reasoning in infancy: The naive theory of rational action. Trends in Cognitive Sciences, 7, 287292. doi: 10.1016/S1364-6613(03)00128-1

Gerson, S., \& Woodward, A. (2013). The goal trumps the means: Highlighting goals is more beneficial than highlighting means in means-end training. Infancy, 18(2), 289-302. doi: 10.111/j.15327078.2012.00112.x

Gerson, S., \& Woodward, A. (2014). Labels facilitate infants' comparison of action goals. Journal of Cognition and Development, 15(2), 197-212. doi:10.1080/15248372.2013.777842

Gerson, S., \& Woodward, A. (2014). Learning from their own actions: The unique effect of producing actions on infants' action understanding. Child Development, 85(1), 264-277. doi: 10.1111/cdev.12115

Gerson, S., \& Woodward, A. (2014). The joint role of trained, untrained, and observed actions at the origins of goal recognition. Infant Behavior and Development, 37(1), 94-104. doi: 10.1016/j. infbeh.2013.12.013

Goodman, N. (1976). Los Lenguajes del Arte. Aproximación a la Teoría de los Símbolos. Seix Barral: Barcelona.

Hamlin, J. K, Hallinan, E. V., \& Woodward, A. L. (2008). Do as I do: 7-month-old infants selectively reproduce others' goals. Developmental Science, 11(4), 487-94. doi: 10.1111/j.1467-7687.2008.00694.x

Harris, P. L., Kavanaugh, R. D., \& Dowson, L. (1997). The depiction of imaginary transformation: Early comprehension of a symbolic function. Cognitive Development, 12, 1-19. doi: 10.1016/ S0885-2014(97)90028-9

Ittelson, W. H. (1996). Visual perception of markings. Psychonomic Bulletin \& Review, 3(2), 171-187. doi: 10.3758/BF03212416

Jauck, D., \& Peralta, O. (2016). La comprensión simbólica temprana de una imagen digital como medio de comunicación y fuente de información. Anales de Psicología, 32(3), 886-892. doi: 10.6018/analesps.32.3.217751

Jovanovic, B., Király, I., Elsner, B., Gergely, G., Prinz, W., \& Aschersleben, G. (2007). The role of effects for infants' perception of action goals. Psychologia, 50, 273-290.

Kellman P. J., \& Spelke E. S. (1983). Perception of partly occluded objects in infancy. Cognitive Psychology, 15, 483-524. doi:10.1016/00100285(83)90017-8

Kirkorian, H. L., Choi, K., \& Pempek, T. A. (2016). Toddlers' word learning from contingent and noncontingent video on touch screens. Child development, 87(2), 405-413. doi: 10.1111/ cdev. 12508

Kirkorian, H .L., \& Pempek, T. (2013). Toddlers and touch screens: Potential for early learning? Zero to Three, 33, 32-37.

Kirkorian, H. L., Wartella, E. A., \& Anderson, D. R. (2008). Media and young children's learning. The Future of Children, 18(1), 39-61. doi: 10.1353/foc. 0.0002

Krcmar, M. (2010). Assessing the research on media, cognitive development, and infants: Can infants really learn from television and videos? Journal of Children and Media, 4(2), 119-134. doi: 10.1080/17482791003629586

Leslie, A. M. (1995). A theory of agency. En D. Sperber, D. Premack \& A. J., Premack (Eds.), 
Causal Cognition: A Multidisciplinary Debate (pp. 121-141). Oxford, UK: Clarendon Press. Marzolf, D. P., \& DeLoache, J. S. (1994). Transfer in young children's understanding of spatial representations. Child Development, 64, 1-15. doi: 10.1111/j.1467-8624.1994.tb00730.x

Meltzoff, A. N. (1995). Understanding the intentions of others: Re-enactment of intended acts by 18-month-old children. Developmental Psychology, 31, 838-850. doi: 10.1037/00121649.31.5.838

Meltzoff, A. N. (1999). Origins of theory of mind, cognition and communication. Journal of Communication Disorders, 32(4), 251-269. doi:10.1016/s0021-9924(99)00009-x

Meltzoff, A. N., \& Moore, M. K. (1997). Explaining facial imitation: A theoretical model. Early Development and Parenting, 6, 179-192. doi: 10.1002/(SICI)1099-0917(199709/12)6:3/4< 179::AID-EDP157>3.0.CO;2-R

Moore, R., Liebal, K., \& Tomasello, M. (2013). Three-year-olds understand communicative intentions without language, gestures, or gaze. Interaction Studies, 14(1), 62-80. doi:10.1075/ is. $14.1 .05 \mathrm{moo}$

Nielsen, M., Simcock, G., \& Jenkins, L. (2008). The effect of social engagement on 24-month-olds' imitation from live and televised models. Developmental Science, 11(5), 722-731. doi: 10.1111/j.1467-7687.2008.00722.x

Onishi K. H., \& Baillargeon, R. (2005). Do 15-month-old infants understand false beliefs? Science, 308(5719), 255-258. doi: 10.1126/science. 1107621

Peralta, O. A., \& Salsa, A. M. (2009). Means of communication and sources of information: Two-year-old children's use of pictures as symbols. The European Journal of Cognition and Development, 21(6), 801-812. doi: 10.1080/09541440802421193

Peralta, O. A., \& Salsa, A. M. (2011). Instrucción y desarrollo en la comprensión temprana de fotografías como objetos simbólicos. Anales de Psicología, 27(1), 118-125.

Premack, D., \& Premack, A. J. (1995). Origins of human social competence. In M. S. Gazzaniga (Ed.), The Cognitive Neurosciences (pp. 205218). Cambridge, MA: MIT Press.

Richert, R. A., Robb, M. B., \& Smith, E. I. (2011). Media as social partners: The social nature of young children's learning from screen media. Child Development, 82(1), 82-95. doi:10.1111/ j.1467-8624.2010.01542.x

Rodríguez S. A. (2012). Los Niños menores de tres años y la televisión: Perspectivas de investigación y debate. Ministerio de Cultura de Colombia. Dirección de Comunicaciones. Bogotá.

Rose, A. (1997). Infants' transfer of response between two-dimensional and three-dimensional stimuli. Child Development, 48, 1086-1091. doi: $10.2307 / 1128366$

Roseberry, S. Hirsh-Pasek K., \& Golinkoff, R. M. (2014) Skype me! Socially contingent interactions help toddlers learn language. Child Development, 85(3), 956-70. doi: 10.1111/ cdev. 12166

Salsa, A. M., \& Peralta, O. A. (2007). Routes to symbolization: Intentionality and correspondence in early understanding of pictures. Journal of Cognition and Development, 8(1), 79-92. doi: 10.1207/s15327647jcd0801_4

Saylor, M. M., Baldwin, D. A., Baird, J. A., \& LaBounty, J. (2007). Infants' on-line segmentation of dynamic human action. Journal of Cognition and Development, 8(1), 113-128. doi: 10.1016/j. cognition.2007.07.005

Schmitt, K. L., \& Anderson, D. R. (2002). Television and reality: Toddlers' use of visual information from video to guide behavior. Media Psychology, 4, 51-76. doi: 10.1207/S1532785XMEP0401 03

Sheenhan, K. J., \& Uttal, D. H. (2016) Children's learning from touch screens: A dual representation perspective. Frontiers in Psychology, 7,1220. doi: 10.3389/fpsyg.2016.01220 
Sigel, I. E. (1978). The development of pictorial comprehension. En B. S. Randhawa \& W. E. Coffman (Eds.), Visual Learning, Thinking and Communication (pp. 93-111). Nueva York: Academic Press.

Sommerville, J. A., Woodward, A. L., \& Needham, A. (2005). Action experience alters 3-month-old infants' perception of others' actions. Cognition, 96, B1-B11. doi: 10.1016/j.cognition.2004.07.004

Spelke, E. S., Phillips, A., \& Woodward, A. L. (1995). Infants' knowledge of object motion and human action. En Causal Cognition: A Multidisciplinary Debate. Symposia of the Fyssen Foundation (pp. 44-78). New York, NY, US: Clarendon Press/Oxford University Press.

Strouse, G. A., \& Ganea, P. A. (2016). Are Prompts Provided by Electronic Books as Effective for Teaching Preschoolers a Biological Concept as Those Provided by Adults? Early Education and Development, 27(8), 1190-1204. doi: 10.1080/10409289.2016.1210457

Strouse, G. A., \& Troseth, G. L. (2008). "Don't try this at home": Toddlers' imitation of new skills from people on video. Journal of Experimental Child Psychology, 101(4), 262-280. doi:10.1016/j. jecp.2008.05.010

Tare, M., Chiong, C., Ganea, P., \& DeLoache, J. S. (2010). Less is more: How manipulative features affect children's learning from picture books. Journal of Applied Developmental Psychology, 31,395-400. doi: 10.1016/j.appdev.2010.06.005

Tomasello, M. (1999). The Cultural Origins of Human Cognition. Cambridge, Mass.: Harvard University Press.

Troseth, G. L. (2003). TV guide: two-year-old children learn to use video as a source of information.
Developmental Psychology, 39(1), 140. doi: 10.1037/0012-1649.39.1.140

Troseth, G. L., \& DeLoache, J. S. (1998). The medium can obscure the message: Young children's understanding of video. Child Development, 69, 950-965. doi: 10.1111/j.1467-8624.1998. tb06153.x

Troseth, G. L., Saylor, M. M., \& Archer, A. H. (2006). Young children's use of video as a source of socially relevant information. Child Development, 77(3), 786-799. doi: 10.1111/j.14678624.2006.00903.x

Walsh, E. (2005). Los Niños Pequeños y los Aparatos Electrónicos. Berkely, California: Childcare Health Program.

Woodward, A. L. (1998). Infants selectively encode the goal object of an actor's reach. Cognition, 69(1), 1-34. doi: 10.1016/S00100277(98)00058-4

Woodward, A. L. (2003). Infants' developing understanding of the link between looker and object. Developmental Science, 6, 297-311. doi:10.1111/1467-7687.00286

Woodward, A. L. (2009). Infants' grasp of others' intentions. Current Directions in Psychological Science, 18, 53-57. doi: 10.1111/j.14678721.2009.01605.x

Woodward, A. L. (2013). Infant foundations of intentional understanding. En: M. R. Banaji \& S. A. Gelman (Eds.). Navigating the Social World: A Developmental Perspective (pp. 7580). Oxford: Oxford University Press.

Zack, E., Barr, R., Gerhardstein, P., Dickerson, K., \& Meltzoff, A. N. (2009). Infant imitation from television using novel touch-screen technology. British Journal of Development Psychology, 27(1), 13-26. doi: 10.1348/026151008X334700

\section{Recibido: Agosto 10, 2016 Aprobado: Febrero 18, 2017}

